\title{
KAJIAN KERUSAKAN SUNGAI YEH KELATING AKIBAT PENAMBANGAN BATU PADAS
}

\author{
Kadek Adi Suryawan ${ }^{1}$, I Nyoman Anom Purwa Winaya ${ }^{2}$, Ni Kadek Sri Ebtha Yuni ${ }^{3}$ \\ 1,2,3 Jurusan Teknik Sipil, Politeknik Negeri Bali, Badung, Indonesia \\ E-mail: ebthayuni@pnb.ac.id
}

\begin{abstract}
Abstrak
Peningkatan kesejahteraan masyarakat telah membawa dampak pada peningkatan berbagai aktivitas masyarakat dalam segala hal. Hal ini membawa dampak positif dari sisi peningkatan pendapatan di sekitar areal penambangan bagi masyarakat sekitar maupun dari pengusaha tambang itu sendiri. Namun dampak negatif lainnya juga tidak kalah akibatnya dilihat dari sisi lingkungan dan sisi hidrolis sungai yaitu rusaknya bentang alam, peningkatan pencemaran air dan udara sekitar penambangan, rusaknya jalan sekitar penambangan, rusaknya penampang sungai serta adanya pembuangan sedimen ke sungai yang berpotensi merusak keanekaragaman hayati wilayah sungai. Berdasarkan hal tersebut diperlukan kajian tentang kerusakan sungai yang terjadi akibat penambangan. Berdasarkan data Kriteria penilaian yang dikeluarkan oleh Fakultas Teknik Universitas Diponegoro, Semarang dapat disimpulkan bahwa penambangan batu padas di Tukad Yeh Kelating indek kinerjanya sebesar di bawah 5 atau kategori rusak berat yang artinya penambangan tersebut sangat merusak sungai dan lingkungan di sekitarnya.
\end{abstract}

Kata kunci: Penambangan batu padas, lingkungan, sungai kelating

\section{PENDAHULUAN}

Menurut Undang-Undang No 11 Tahun 1974 tentang pengairan, wilayah sungai memiliki pengertian kesatuan wilayah pengelolaan sumber daya air dalam satu atau lebih daerah aliran sungai dan/atau pulau-pulau kecil yang luasnya kurang dari atau sama dengan $2000 \mathrm{~km} 2$ (Maryono, 2003). Sedangkan Daerah aliran sungai adalah suatu wilayah daratan yang merupakan satu kesatuan dengan sungai dan anak-anak sungainya, yang berfungsi menampung, menyimpan, dan mengalirkan air yang berasal dari curah hujan ke danau atau ke laut secara alami, yang batas di darat merupakan pemisah topografis dan batas di laut sampai dengan daerah perairan yang masih terpengaruh aktivitas daratan (Sumarto, 1985). Dalam pengelolaan sumber daya air ada beberapa upaya yaitu: merencanakan, melaksanakan, memantau, dan mengevaluasi penyelenggaraan konservasi sumber daya air, pendayagunaan sumber daya air, dan pengendalian daya rusak air (Kodoatie, 2005)

Berdasarkan Pasal 21 Peraturan Pemerintah Nomor 35 Tahun 1991 tentang Sungai, untuk pelindungan palung sungai perlu dilakukan pengaturan pengambilan komoditas tambang di sungai, dan juga berdasarkan Pasal 59 ayat (5) Peraturan Pemerintah Nomor 35 Tahun 1991 tentang Sungai, izin pengambilan komoditas tambang di sungai diberikan oleh bupati/walikota sesuai ketentuan peraturan perundang-undangan setelah mendapat rekomendasi teknis dari pengelola sumber daya air. Sehingga perlu dilakukan kajian/studi terkait dengan kerusakan sungai yang timbul akibat dari aktivitas pertambangan. Dalam penelitian ini diharapkan dapat mengidentifikasi dan mengkaji secara teknis terkait kerusakan sungai yang timbul akibat dari aktivitas pertambangan berdasarkan pada aspek teknik serta peraturan yang berlaku.

\section{METODE PENELITIAN}

Pelaksanaan penelitian secara garis besar dilaksanakan/dilakukan dalam bentuk pengumpulan informasi (pengumpulan data sekunder dan primer), survei lapangan, analisis permasalahan, serta perumusan penilaian kerusakan sungai serta rumusan penyelesaian permasalahannya. Waktu peneltian untuk penyusunan Kajian Penanaganan Alur Tukad Kelating di Kabupaten Tabanan adalah selama lima bulan. Lokasi studi berada di wilayah DAS Tukad Kelating, Desa Kelating, Kecamatan Kediri, Kabupaten Tabanan.

Keberadaan dan sumber data kiranya merupakan bagian yang sangat penting terkait dengan validitas data yang didinginkan. Berkenaan dengan data yang akan diambil maka sumber data yang akan diacu adalah sebagai berikut (a) data curah hujan hariam maksimum tahunan diperoleh dari Badan Meteorologi, Klimatologi dan Geofisika wilayah III Bali di jalan 
Raya Tuban. Seri data hujan yang diambil minimal 10 tahun terakhir, (b) data sungai diperoleh dari Balai Wilayah Sungai Bali Penida, Komplek Kantor PU Jalan Cok Agusng Tresna, Denpasar, (c) data existing sungai diperoleh melalui pengukuran dan pengamatan langsung di lapangan, (d) data kegiatan penambangan dari Dinas PU Tabanan dan bagian ESDM Dinas PU Provinsi Bali, (e) kebijakan pengembangan Tukad Kelating diperoleh dari Balai Wilayah Sungai Bali Penida, DPU dan BAPPEDA Kabupaten Tabanan.

Analisis data yang dilakukan dalam penelitian ini adalah analisis hidrologi, analisis kapasitas dan hidrolika, analisis kegiatan penambangan, analisis kerusakan sungai.

\section{HASIL DAN PEMBAHASAN}

\section{Analisa Hidrometri}

Analisa hidrometri mencakup analisa debit sesaat dan analisa terhadap sedimentasi yang terjadi.

\section{Analisa Debit Sesaat}

Analisa debit sesaat merupakan analisa yang dilakukan untuk mengetahui debit yang mengalir pada suatu ruas sungai. Metode pengukuran dilakukan dengan metode pias yang mengambil bentang sungai menjadi beberapa pias dengan kecepatan dan kedalam tertentu. Metode pengukuran ini mengacu kepada metode pengukuran debit sesaat SNI $03-2414-1991$ Puslitbang Pengairan Kementerian Pekerjaan Umum dan Perumahan Rakyat.

\section{Analisa Sedimentasi}

Analisa sedimentasi dilakukan untuk mengetahui kandungan sedimen terutama sedimen layang dan sedimen dasar yang terbawa dalam aliran air serta analisa sedimen yang ada di wilayah DAS. Analisa sedimen layang dilakukan melalui pengamatan terhadap sample air yang diambil yang dilakukan di Laboratorium Hidrolika dan Lingkungan Politeknik Negeri Bali. Pengambilan sample dilapangan terutama sekali dilakukan pada daerah di sebelah hilir lokasi penambangan. Adapun metode penentuan besarnya sedimen layang yang terkandung dalam air adalah sebagai berikut :(1). Ambil sample air hasil pengambilan sample lapangan, (2). Taruh sample air dalam alat pengukur kandungan sedimen TDS, (3). Tuangkan regent dalam sample air dan (4). Baca nilai TDS nya. Adapun hasil analisa sedimentasi layang di Tukad Klating menunjukkan hasil sebesar 862 $\mathrm{mg} / \mathrm{lt}$. Hal ini menunjukkan bahwa kandungan sedimen yang ada signifikan mempengaruhi kondisi air yang ada di wilayah tersebut.

\section{Analisa Kualitas Air}

Analisa kwalitas air dilakukan untuk mengetahui kandungan yang terkandung dalam aliran air. Pameter yang diuji dari sample air meliputi BOD, COD, Suhu, PH serta pengujian kimia lainnya. Dari pengujian yang dilakukan menunjukkan bahwa aktifitas tambang yang dilakukan di wilayah sungai tidak terlalu berpengaruh terhadap menurunnya kualitas air. Meskipun secara visual terjadi kekeruhan pada areal penambangan di alur sungai namun jika dibandingkan dengan volume air yang mengalir maka dapat disimpulkan tidak terjadi penurunan kwalitas air pada daerah penambangan. Hasilnya nanti dibandingkan dengan peraturan Gubernur Bali Tahun 2007 tentang baku mutu air. Metode pengujian kwalitas air di Laboratorium adalah sebagai berikut: (1) Masukkan air dalam gelas ukur, (2) Tambahkan zat pelarut kimia (regent), (3) Hidupkan mesin pengujian, (4) Baca nilai setiap pengujian. Hasil pengujian kualitas air dari laboratorium menunjukkan bahwa sungai Yeh Kelating nilai kekeruhannya melebihi ambang batas dari nilai yang diperbolehkan sebesar 5 NTU namun dari pengujian yang dilakukan menunjukkan nilai 413 di bagian hulu dan 413,5 di bagian hilir. Dari pengamatan visual yang dilakukan maka air tampak sangat keruh dan tidak memungkinkan dipakai air untuk mandi dan mencuci.

\section{Analisa Hidrologi}

Analisa hidrologi merupakan analisa yang dilakukan untuk mengetahui besarnya curah hujan rancangan dan banjir rancangan. Penentuan curah hujan dan banjir rancangan dibuat dalam beberapa kala ulang.

\section{Penentuan Stasiun Hujan}

Penentuan stasiun hujan sangat penting karena akan berpengaruh terhadap besaran nilai curah hujan dan banjir rancangan yang dihasilkan. Penentuan stasiun hujan didasarkan kepada keberadaan data yang ada pada stasiun tersebut serta keberadaan stasiun itu sendiri dalam kawasan DAS. Pada studi ini stasiun yang dipergunakan adalah stasiun hujan Kerambitan. Untuk pengujian validitas dipakai metode Outliner dan metode RAPS.

Tabel 1. Uji Outliner Stasiun Kerambitan

\begin{tabular}{ccccc}
\hline No & Tahun & $\begin{array}{c}\text { Curah } \\
\text { Hujan } \\
\text { Maksimum } \\
(\mathrm{mm})\end{array}$ & Log R & $\begin{array}{c}\text { (log R- } \\
\text { Log } \\
\text { Rrerata })^{2}\end{array}$ \\
\hline 1 & 1999 & 206 & 2.314 & 0.051 \\
\hline 2 & 2000 & 210 & 2.322 & 0.055 \\
\hline 3 & 2001 & 84 & 1.924 & 0.027 \\
\hline 4 & 2002 & 122 & 2.086 & 0.000 \\
\hline 5 & 2003 & 125 & 2.097 & 0.000 \\
\hline 6 & 2004 & 95 & 1.978 & 0.012 \\
\hline 7 & 2005 & 116 & 2.064 & 0.001 \\
\hline
\end{tabular}




\begin{tabular}{ccccc}
\hline 8 & 2006 & 124 & 2.093 & 0.000 \\
\hline 9 & 2007 & 97 & 1.987 & 0.010 \\
\hline 10 & 2008 & 128 & 2.107 & 0.000 \\
\hline 11 & 2009 & 130 & 2.114 & 0.001 \\
\hline 12 & 2010 & 122 & 2.086 & 0.000 \\
\hline 13 & 2011 & 120 & 2.079 & 0.000 \\
\hline 14 & 2012 & 121 & 2.083 & 0.000 \\
\hline 15 & 2013 & 98 & 1.991 & 0.009 \\
\hline Jumlah & & & $\mathbf{3 1 . 3 2 7}$ & $\mathbf{0 . 1 6 6}$ \\
\hline Rata-rata & $=$ & $\mathbf{2 . 0 8 8}$ & \\
& & &
\end{tabular}

sungai sangat diperlukan besaran banjir rancangan untuk menentukan dimensi bangunan agar tidak under estimate maupun over estimate. Besaran kala ulang banjir yang digunakan tergantung pada jenis bangunan yang akan dibangun, karena itu diperlukan hidrograf banjir dengan berbagai kala ulang. Hidrograf banjir diperoleh dengan mengalikan hujan efektif dengan hidrograf satuan.

\section{Distribusi Hujan}

Distribusi curah hujan adalah berbedabeda sesuai jangka waktu yang ditinjau yaitu curah hujan tahunan, curah hujan bulanan, curah hujan harian dan curah hujan per jam. Curah hujan jangka pendek dinyatakan dalam intensitas per jam yang disebut intensitas curah hujan. Intensitas curah hujan dalam studi ini ditentukan berdasarkan persamaan empiris yaitu persamaan Mononobe yang digunakan untuk menghitung intensitas curah hujan setiap waktu berdasarkan data curah hujan harian seperti persamaan berikut :

$I=\frac{R 24}{24}\left(\frac{24}{t}\right)^{\mathrm{m}}$

Dengan:

I = intensitas curah hujan ( $\mathrm{mm} / \mathrm{jam})$,

$\mathrm{t}=$ lamanya curah hujan (jam),

$\mathrm{m}=$ konstanta,

R24 = curah hujan maksimum dalam 24 jam (mm).

Lamanya curah hujan diperoleh dari data hujan otomatik, namun di lokasi penelitian tidak terdapat pencatatan hujan otomatik karena itu durasi hujan dan waktu konsentrasi ditentukan dengan persamaan Kirpich sebagai berikut:

$t_{c}=\left(\frac{0.87 L^{2}}{1000 S}\right)^{0.385}$

\begin{tabular}{cccc}
\hline 1 & 2 & -0.1915 & 117.04 \\
\hline 2 & 5 & 0.7741 & 150.18 \\
\hline 3 & 10 & 1.3756 & 175.42 \\
\hline 4 & 20 & 1.8632 & 198.96 \\
\hline 5 & 25 & 2.107 & 211.89 \\
\hline 6 & 50 & 2.6439 & 243.39 \\
\hline 7 & 100 & 3.1433 & 276.9 \\
\hline 8 & 200 & 3.6301 & 313.99 \\
\hline 9 & 1000 & 4.6854 & 412.35 \\
\hline
\end{tabular}

Analisa Banjir Rancangan

Dalam desain suatu analisis kapasitas

dengan:

$\begin{array}{ll}\mathrm{t}_{\mathrm{c}} & =\text { waktu } \text { konsentrasi }(\mathrm{jam}) \\ \mathrm{L} & =\text { panjang sungai }(\mathrm{km}) \\ \mathrm{S} & =\text { kemiringan rata-rata sungai }\end{array}$

Hujan Efektif

Hujan efektif adalah bagian hujan total yang menghasilkan limpasan langsung (direct runoff). Limpasan langsung ini terdiri atas limpasan permukaan (surface run-off) dan interflow.

Dengan menganggap bahwa proses tranformasi hujan menjadi limpasan langsung mengikuti proses 
linier dan tidak berubah oleh waktu, maka hujan efektif $\left(R_{n}\right)$ dapat dinyatakan sebagai berikut :

$$
\mathrm{R}_{\mathrm{n}} \quad=\mathrm{C} \times \mathrm{R}
$$

Dengan :

$\mathrm{Rn} \quad=$ hujan efektif ( $\mathrm{mm} /$ hari)

C = koefisien limpasan

$\mathrm{R} \quad=$ intensitas hujan $(\mathrm{mm} /$ hari)

\section{Hidrograf Banjir Rancangan}

Hasil perhitungan banjir rancangan selengkapnya dapat dilihat pada tabel berikut.

Tabel 3. Hidrograf Banjir Nakayasu Tukad Kelating

\begin{tabular}{|c|c|c|c|c|c|c|c|}
\hline $\mathbf{T}$ & Q2 & Q5 & Q10 & Q20 & Q25 & Q50 & Q100 \\
\hline 0.00 & 0.00 & 0.00 & 0.00 & 0.00 & 0.00 & 0.00 & 0.00 \\
\hline 1.00 & 10.54 & 13.52 & 15.79 & 17.91 & 19.07 & 21.91 & 24.93 \\
\hline 2.00 & 58.34 & 74.87 & 87.45 & 99.18 & 105.63 & 121.34 & 138.04 \\
\hline 3.00 & 55.79 & 71.59 & 83.62 & 94.85 & 101.01 & 116.03 & 132.00 \\
\hline 4.00 & 45.16 & 57.94 & 67.68 & 76.76 & 81.75 & 93.91 & 106.84 \\
\hline 5.00 & 30.02 & 38.52 & 45.00 & 51.04 & 54.35 & 62.43 & 71.03 \\
\hline 6.00 & 20.81 & 26.70 & 31.19 & 35.37 & 37.67 & 43.27 & 49.23 \\
\hline 7.00 & 14.94 & 19.17 & 22.39 & 25.40 & 27.05 & 31.07 & 35.35 \\
\hline 8.00 & 10.96 & 14.07 & 16.43 & 18.63 & 19.85 & 22.80 & 25.94 \\
\hline 9.00 & 8.21 & 10.53 & 12.30 & 13.96 & 14.86 & 17.07 & 19.42 \\
\hline 10.00 & 6.36 & 8.16 & 9.53 & 10.81 & 11.51 & 13.22 & 15.04 \\
\hline 11.00 & 5.00 & 6.42 & 7.49 & 8.50 & 9.05 & 10.40 & 11.83 \\
\hline 12.00 & 3.96 & 5.09 & 5.94 & 6.74 & 7.18 & 8.24 & 9.38 \\
\hline 13.00 & 3.14 & 4.03 & 4.71 & 5.34 & 5.69 & 6.53 & 7.43 \\
\hline 14.00 & 2.49 & 3.20 & 3.73 & 4.23 & 4.51 & 5.18 & 5.89 \\
\hline 15.00 & 1.97 & 2.53 & 2.96 & 3.36 & 3.58 & 4.11 & 4.67 \\
\hline 16.00 & 1.57 & 2.01 & 2.35 & 2.66 & 2.83 & 3.26 & 3.70 \\
\hline 17.00 & 1.24 & 1.59 & 1.86 & 2.11 & 2.25 & 2.58 & 2.94 \\
\hline 18.00 & 0.98 & 1.26 & 1.47 & 1.67 & 1.78 & 2.05 & 2.33 \\
\hline 19.00 & 0.78 & 1.00 & 1.17 & 1.33 & 1.41 & 1.62 & 1.84 \\
\hline 20.00 & 0.62 & 0.79 & 0.93 & 1.05 & 1.12 & 1.29 & 1.46 \\
\hline 21.00 & 0.49 & 0.63 & 0.73 & 0.83 & 0.89 & 1.02 & 1.16 \\
\hline 22.00 & 0.39 & 0.50 & 0.58 & 0.66 & 0.70 & 0.81 & 0.92 \\
\hline 23.00 & 0.31 & 0.40 & 0.46 & 0.52 & 0.56 & 0.64 & 0.73 \\
\hline 24.00 & 0.24 & 0.31 & 0.37 & 0.41 & 0.44 & 0.51 & 0.58 \\
\hline
\end{tabular}

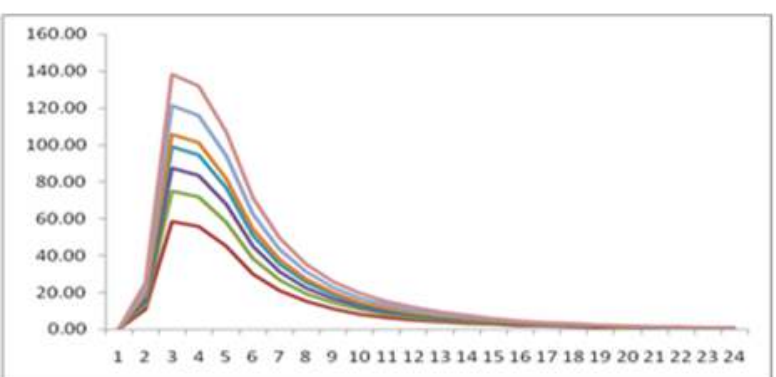

\section{Gambar 1. Hidrograf Banjir Tukad Klating}

Hasil analisis menunjukkan bahwa banjir Tukad Klating puncaknya akan terjadi pada jam ke 2 setelah hujan pertama kali terjadi. Dalam analisis kapasitas sungai dengan tipikal sungai kecil maka debit yang akan dipakai adalah dengan kala ulang 25 tahun sekali (Q25) sebesar 105,63 m³/dt.

\section{Analisa Hidrolika}

Analisa hidrolika dilakukan untuk mengetahui kapasitas sungai dibandingkan dengan banjir dengan kala ulang yang tertentu. Dari observasi lapangan di peroleh data sebagai berikut :

Lebar sungai $(\mathrm{L}): 9 \mathrm{~m}$

Tinggi tebing : $3 \mathrm{~m}$

Kemiringan dasar sungai : 0,008

Debit maksimal yang bisa di lewatkan sebesar $102,29 \mathrm{~m} 3 / \mathrm{dt}$, ini artinya secara hidrolis Tukad Kelating masih mampu melewatkan debit banjir dengan kala ulang 25 tahun sekali sebesar 105, 63 karena perbedaan kapasitas yang ada dengan banjir yang akan terjadi hamper mirip.

\section{Analisa Kerusakan Sungai}

Analisa terhadap kerusakan sungai didasarkan kepada beberapa kritera berdasarkan Konsep Pedoman Inventaisasi Kondisi Sungai dan Bangunan yang dikeluarkan oleh Kementerian Pekerjaan Umum dan berdasarkan kriteria kerusakan areal penambangan yang dikeluarkan oleh Fakultas Teknik UNDIP tahun 2011 yang menekankan kepada teknik penambangan, kecepatan penambangan, kedalaman tebing galian, tingkat erosi menghasilkan indek kerusakan yang dipakai sebagai dasar penilaian kerusakan.

Berdasarkan data Kriteria penilaian yang dikeluarkan oleh Kementerian Pekerjaan Umum dan Perumahan Rakyat dapat disimpulkan bahwa penambangan batu padas di Tukad Yeh Klating indek kinerjanya sebesar 49,54 atau di bawah 50 yang artinya penambangan tersebut sangat merusak sungai dan lingkungan di sekitarnya. Tabel 4 menunjukkan penilaian kinerja penambangan batu Padas Tukad Yeh Kelating.

Tabel 4. Kerusakan Sungai Akibat Penambangan Berdasarkan Keputusan Menteri Pekerjaan Umum dan Perumahan Rakyat 


\begin{tabular}{|c|c|c|c|c|c|c|c|c|c|}
\hline & $\begin{array}{c}\text { Nama } \\
\text { Sunga } \\
\mathbf{i}\end{array}$ & 3 & 4 & 5 & 6 & 7 & 8 & 9 & 10 \\
\hline 1 & $\begin{array}{l}\text { TUKA } \\
\text { D YEH } \\
\text { KLAN } \\
\text { TING } \\
\end{array}$ & 60 & 60 & 75 & 75 & 71 & 60 & 0 & 51 \\
\hline \multirow[b]{2}{*}{ No } & \multicolumn{9}{|c|}{ Aktifitas Operasional } \\
\hline & $\underset{i}{\text { Sunga }}$ & 11 & 12 & 13 & 14 & 15 & 16 & 17 & 18 \\
\hline 1 & $\begin{array}{l}\text { TUKA } \\
\text { D YEH } \\
\text { KLAN } \\
\text { TING }\end{array}$ & 51 & 71 & 20 & 20 & 30 & 644 & $\begin{array}{c}49.5 \\
4\end{array}$ & $\begin{array}{c}\text { Ru } \\
\text { sa } \\
k \\
\text { be } \\
\text { rat }\end{array}$ \\
\hline
\end{tabular}

Dengan:

3 (penyempitan), 4 (Erosi Dasar), 5 (Longsoran Tebing Kanan), 6 (Longsoran Tebing Kiri), 7 (Kepadatan Tanaman dan bantaran), 8 (Sedimentasi di dasar sungai), 9 (Penetapan Garis Sepadan), 10 (Aliran pada muara sungai), 11 (Hambatan air), 12 (Aktifitas penambangan sedimen pada alur), 13 (Aktifitas penambangan sedimen pada bantaran), 14 (Pemanfaatan Daeran Sempadan Luar Tanggul), 15 (Buangn Air Limbah), 16 (Jumlah total), 17 (Rata-rata), 18 (Keterangan).

\section{PENUTUP}

Berdasarkan data Kriteria penilaian yang dikeluarkan oleh Oleh Fakultas Teknik Universitas Diponegoro, Semarang dapat disimpulkan bahwa penambangan batu padas di Tukad Yeh Kelating indek kinerjanya sebesar di bawah 5 atau kategori rusak berat yang artinya penambangan tersebut sangat merusak sungai dan lingkungan di sekitarnya.

\section{UCAPAN TERIMAKASIH}

Pada kesempatan ini penulis mengucapkan terima kasih yang sebesar-besarnya kepada keluarga yang selalu memberikan semangat dan motivasi dalam melakukan penelitian. Ucapan terima kasih juga penulis sampaikan kepada tim peneliti yang meluangkan waktu untuk survey pencarian data.

\section{DAFTAR PUSTAKA}

Agus Maryono, 2003. Pembangunan Sungai Dampak Dan Restorasi Sungai . Yogyakarta : Universitas Gajah Mada Press.

Balai Penelitian dan Pengembangan Pengairan.2000. Standar Nasional Indonesia : Perhitungan Banjir Rancangan. Jakarta : Departemen Pekerjaan Umum, Bidang Sumber Daya Air.

BPS Kabupaten Karangasem,2012. Karangasem Dalam Angka 2012. Amlapura : Pemerintah
Daerah Kabupaten Karangasem.

CD. Sumarto, 1985. Hidrologi Teknik. Surabaya : Usaha Nasional

Kodoatie, Robert dan Sjarief, Rustam, 2005. Pengelolaan Sumber Daya Air Terpadu. Yogyakarta: Andi

Linsley, R.K dan Franzini, Josep B. 1995. Teknik Sumber Daya Air. An Jakarta: Erlangga

Santoso, Gempur. 2005. Fundamental Metodologi Penelitian Kuantitatif dan Kualitatif. Jakarta: Prestasi Pustaka

Sharin, 1990. Statistical Of Hidrology. Mc.Graw Hill

Sri Harto.1993. Analisa Hidrologi. Jakarta : PT. Gramedia Pustaka Utama

Suwarno.1991. Hidrologi : Pengukuran Dan Pengolahan Data Aliran Sungai. Bandung : Nova

Suyono Sosrodarsono dkk. 1993. Hidrologi Untuk Pengairan. Jakarta : Pradnya Paramita

Suyono Sosrodarsono dkk. 1985. Perbaikan dan Pengaturan Sungai. Jakarta : Pradnya Paramita

Tantra, DK. 2000. Pendekatan Penelitian Kuantitatif Dalam Penelitian Sosial Prilaku. Singaraja: IKIP Negeri Singaraja.

Ven Te Chow, 1987. Hidrolika Saluran Terbuka. Jakarta : Erlangga 